\title{
Height and seriousness of crime in XYY men
}

\author{
ERNEST B. HOOK AND KRISTINE M. HEALY
}

From the Epidemiology and Human Ecology Section, Birth Defects Institute, New York State Department of Health; and Department of Pediatrics, Albany Medical College of Union University, Albany, New York 12208, USA

SUMMARY The case histories of XYY males in two security settings were ranked by degree of seriousness of crime. The correlations of these scores with height were either zero (for data of Daly with the history of the propositus excluded) or positive (for data of Jacobs et al., $\mathrm{P}<0.05$ ). For both studies, the results were contrary to the expectation of negative correlation which would be found if, in accord with Hunter's suggestion, authorities were biased to place XYYs in security settings because of the more threatening appearance associated with larger stature.

In 1966, H. Hunter, commenting on the increased frequency of XYYs in certain types of security settings, suggested that because of their great height and build they would present such a frightening picture that the court and psychiatrists would be biased to direct them to special hospitals for community safety'.

While not all XYYs are of huge stature, they are, on average, much taller than the average adult male. If greater height were a strong contributing factor to the greater prevalence of XYYs in security settings for reasons similar to those suggested by Hunter then, as has been noted elsewhere (Hook, 1973), the seriousness of the crimes of tall XYYs in custody should be, on the average, less than those of shorter XYYs, other factors being equal, and the correlation between height and seriousness of crime should be negative. From another viewpoint, for every 20 XYY men in a 'mental-penal' setting typical of those reported to date, about $1 \mathrm{XYY}$ would be expected on the basis of the frequency of the genotype in the newborn population (Hook, 1973). If Hunter's suggestion accounts for the excess, then the rest should be primarily very tall men who had committed relatively trivial crimes and in general the taller the man, the more trivial the behaviour that got him into or retained him in custody.

We report here the results of a search for such a correlation.

\section{Subjects and methods}

We found two reports of XYYs detected in security Received for publication 17 August 1976 settings in which at least 5 individuals were detected, the heights of each were reported, and individual criminal histories were provided. The first from the United Kingdom (Jacobs et al., 1968) and the second from the USA (Daly, 1969a, b).

The case histories of each individual described in each study were reviewed by one of us (K.M.H.) who physically removed from copies of the text all reference, direct or indirect, to stature. All case descriptions were then cut out, remounted, and photoduplicated in a manner such that a 'coded' history that made no mention of height was available for each individual. It could not be told from which history the information concerning stature had been removed.

These coded histories were then read by E.B.H. and N.H.H. (see acknowledgement) who independently assigned a score from 0 to 12 to the histories based on the seriousness of the crime. About three weeks after she had reviewed and edited the case descriptions, K.M.H. (without knowledge of the scores of E.B.H. or N.H.H.) also independently assigned a 0-12 score to each history. The scale used by E.B.H. was $0,6,12$, and by N.H.H. and K.M.H. $0,3,6,9,12$. Each observer made a separate independent judgement as to the relative seriousness of the reasons for incarceration, but in general each assigned greatest weight to acts of violence against individuals and less weight to crimes involving property, escape, or homosexuality.

N.H.H. had never read the unedited case histories before. K.M.H. had read them three weeks earlier and had no (conscious) recollection of from which histories the height data had been removed at 
the time of scoring. E.B.H. had reviewed the histories three years earlier, and at the time of the scoring recalled only the details of case 10 of Daly. It was in fact the observations in this particular case that prompted the investigations reported here rather than the remarks of Hunter quoted above. We have, therefore, treated case 10 as an 'index case' or propositus in some of the analyses here and the correlations are presented on data with him excluded, and then included. The relative rankings of the histories by each observer were quite similar, and there were no obvious discrepancies, for each history. Ranks $(1,2,3 \ldots)$ were assigned based on the total scores and, where there were ties on the total score, the case histories of those with ties were reviewed and ties broken for the purposes of assigning unequivocal ranks, as noted in the table. The codes for the histories were then broken, the heights deciphered, and the product-moment correlation coefficients $r$ of height with total history score were calculated. Since this method might be sensitive to the particular intervals used for distinguishing degree of seriousness of crime, $r$ was also calculated using the rank score for crime. The first method is sensitive to assumptions about how much more serious a history of murder is for example, than a history of larceny; the second only rank orders such histories. The productmoment correlation coefficient is applicable with rank orders if the other variable, in this case height of XYYs, is normally distributed (Snedecor and Cochran, 1967). Sparse published data suggest that this is the case (Casey et al., 1973) but use of a nonparametric approach, e.g. the Spearman rank correlation coefficient $r_{s}$ avoids dependence upon this assumption (Snedecor and Cochran, 1967). Therefore, this coefficient was also calculated.

\section{Results}

The results are presented in Tables 1 and 2 . In neither study (with propositus excluded) was a negative correlation found using any method of calculation.

\section{Discussion}

The interrelation of height with behaviour and position in society is likely to be complex. This study could look only indirectly for a strong effect stature might have had upon the relative likelihood of an XYY male being placed or maintained in a maximum security setting by authorities. But in both jurisdictions the data suggest that Hunter's explanation is unlikely to be a strong contributory factor to the increased frequency of adult XYYs in security settings, though of course, in occasional instances such as that of case 10 of Daly, it may play an important role. The
Table 1

Scoring of history

\begin{tabular}{llll} 
History score & Total & $\begin{array}{l}\text { History§ } \\
\text { rank }\end{array}$ & $\begin{array}{l}\text { Height } \\
(\mathrm{cm})\end{array}$ \\
\hline E.B.H. $\quad$ K.M.H. & N.H.H. & &
\end{tabular}

\begin{tabular}{lcrrrrl}
\hline \multicolumn{2}{l}{ Cases of Jacobs et al. } & & & & \\
H & 0 & 0 & 0 & 0 & 1 & 171 \\
I & 0 & 3 & 0 & 3 & 2 & 184 \\
B & 6 & 0 & 0 & 6 & 3 & 175 \\
E & 0 & 3 & 3 & 6 & 4 & 181 \\
F & 6 & 3 & 3 & 12 & 5 & 186 \\
C & 6 & 3 & 3 & 12 & 6 & 177 \\
D & 12 & 9 & 6 & 27 & 7 & 183 \\
A & 12 & 9 & 9 & 30 & 8 & 186 \\
G & 12 & 12 & 12 & 36 & 9 & 188 \\
\hline
\end{tabular}

\section{Cases of Daly $\dagger$}

\begin{tabular}{crrrrrr}
8 & 0 & 0 & 0 & 0 & 1 & 198 \\
$10^{*}$ & 0 & 3 & 3 & 6 & 2 & 203 \\
5 & 0 & 3 & 3 & 6 & 3 & 182 \\
9 & 0 & 3 & 3 & 6 & 4 & 188 \\
1 & 6 & 0 & 3 & 9 & 5 & 196 \\
3 & 6 & 9 & 6 & 21 & 6 & 185 \\
6 & 6 & 9 & 6 & 21 & 7 & 182 \\
7 & 12 & 9 & 9 & 30 & 8 & 185 \\
$2 \ddagger$ & 12 & 12 & 12 & 36 & 9 & 193 \\
$4 \ddagger$ & 12 & 12 & 12 & 36 & 10 & 198 \\
\hline
\end{tabular}

* = 'propositus'.

†Case numbers listed in this table are those of Daly (1969a) which provide the case histories. The heights were given in Daly (1969b), though different case numbers were used for the same individuals in that report.

¥Crimes included murder or manslaughter.

$\S$ Ties were broken after re-review of case histories.

\section{Table 2}

\section{Correlations of history and height*}

\begin{tabular}{llll}
\hline & $\begin{array}{l}\mathrm{r} \text { with } \\
\text { total } \\
\text { history } \\
\text { score }\end{array}$ & $\begin{array}{l}\mathrm{r} \text { with } \\
\text { ranked } \\
\text { history } \\
\text { score }\end{array}$ & $\begin{array}{l}\mathrm{r}_{\text {s with }} \\
\text { ranked } \\
\text { history } \\
\text { and height } \\
\text { scores }\end{array}$ \\
\hline $\begin{array}{l}\text { Report of Jacobs } \text { et ul., } \mathrm{n}=9 \\
\begin{array}{l}\text { Report of Daly-without } \\
\text { propositus, } \mathrm{n}=9\end{array}\end{array}$ & $+0.69 \dagger$ & $+0.68 \dagger$ & $+0.70 \dagger$ \\
[With propositus, $\mathrm{n}=10]$ & +0.03 & +0.09 & +0.10 \\
{$[-0.14]$} & {$[-0.20]$} & {$[-0.18]$}
\end{tabular}

*95\% confidence limits may be calculated for the data of Daly in the 1st column, assuming normality of both variables, as $(-0.65+0.68)$ for $n=9$, and $(-0.71,+0.54)$ for $n=10$. For coefficients based on ranked scores (columns two and three) $95 \%$ confidence limits for $r$ and $r_{s}$ are not readily calculable, but the probabilities of excluding the null hypothesis by chance alone are all $>0.05$ except where indicated. $+\mathrm{P}<0.05$.

correlations for both studies (with the index case excluded) are not negative. (In fact $r$ and $r_{s}$ in the data from Jacobs $e t$ al. are strongly positive and significantly different from zero.)

Our study has made the implicit assumption that our evaluations of the relative seriousness of crime are similar to those of the authorities responsible for either sentencing or maintaining in custody those XYY men whose histories were reviewed. Certainly such judgments may vary from jurisdiction to jurisdiction, and between authorities within jurisdictions. 
A rough independent check on our own results, however, may be provided by comparing the heights of those who committed murder or manslaughter with the remainder. Crimes against human life, the crimes of the XYYs in custody, would be expected to be judged ubiquitously as the most serious. In the data of Daly the mean (and median) heights of those who had committed murder or manslaughter was 195.5 cm compared with 189.9 (mean) and $186.5 \mathrm{~cm}$ (median) for the remainder. In Jacobs' data, the sole murderer was the tallest in the series. These observations are thus consistent with the trend obtained by use of our other approach.

Results of studies of the heights of XY individuals in security settings in which the rate of XYYs is known to be increased have not revealed consistent evidence for an overrepresentation of very tall individuals (Hook, 1973; Casey et al., 1973) nor to our knowledge have other studies of heights of delinquents in the USA (Borgaonkar et al., 1972; Glueck and Glueck, 1950). Thus two quite separate, albeit indirect, approaches provide no grounds for believing that Hunter's suggestion explains any significant increments of XYYs in custody, though we emphasize, in exceptional cases, it may be valid.
We thank Norma H. Hatcher for reviewing case histories.

\section{References}

Borgaonkar, D. S., Ungar, W. M., Moore, S. M., and Crofton, T. A. (1972). 47, XYY syndrome, height and institutionalization of juvenile delinquents. British Journal of Psychiatry, 120, 549-550.

Casey, M. D., Blank, C. E., McLean, T. M., Kohn, P., Street, D.R.K., McDougall, J. M., Gooder, J., and Platts, J. (1973). Male patients with chromosome abnormality in two state hospitals. Journal of Mental Deficiency Research, 16, 215 256.

Daly, R. F. (1969a). Neurological abnormalities in XYY males. Nature, 221, 472-473.

Daly, R. F. (1969b). Mental illness and patterns of behavior in 10 XYY males. Journal of Nervous and Mental Disease, 149, 318-327.

Glueck, S. and Glueck, E. (1950). Unravelling Juvenile Delinquency, pp. 184-185. Commonwealth Fund, New York.

Hook, E. B. (1973). Behavioral implications of the human XYY genotype. Science, 179, 139-150.

Hunter, H. (1966). YY chromosomes and Klinefelters syndrome. Lancet, 1, 984.

Jacobs, P. A., Price, W. H., Court Brown, W. M., Brittain, R. P., and Whatmore, P. N. (1968). Annals of Human Genetics, 31, 339-357.

Snedecor, G. W. and Cochran, W. G. (1967). Statistical Methods, pp. 193-194. Iowa State University Press, Ames, Iowa. 